Original Research Paper

\title{
Bimbingan dan Konseling Mahasiswa yang Berbasis Sistem Pakar dengan Menggunakan Metode Faktor Kepastian
}

\author{
Alvin Rangga Novaliyan', Atman Lucky Fernandes', Pratiwi Hendro Wahyudiono ${ }^{2}$, \\ Afdal Suganda ${ }^{3}$, Maria Olva ${ }^{4}$, Ismail ${ }^{1}$, Nur Iksan ${ }^{5}$, Achmad Yani $^{6}$, Ismail Yusuf Panessai ${ }^{7}$ \\ ${ }^{1}$ Fakultas Teknik, Universitas Ibnu Sina. Batam, Indonesia. \\ ${ }^{2}$ Fakultas Teknik, Universitas Andalas. Padang, Indonesia. \\ ${ }^{3}$ PT. TEC Indonesia. Kepulauan Riau, Indonesia. \\ ${ }^{4}$ PT. Prima Labeling. Batam, Indonesia. \\ ${ }^{5}$ Fakultas Teknik, Universitas Riau Kepulauan (UNRIKA). Batam, Indonesia. \\ ${ }^{6}$ Teknik Perkapalan, Fakultas Teknik, Universitas Hasanuddin. Makassar, Indonesia. \\ ${ }^{7}$ Fakulti Seni, Komputeran \& Industri Kreatif, Universiti Pendidikan Sultan Idris, \\ Malaysia.
}

\section{Article History \\ Received: \\ 11.07.2021 \\ Revised: \\ 27.07.2021 \\ Accepted: \\ 02.08 .2021 \\ *Corresponding Author: \\ Alvin Rangga Novaliyan \\ Email: \\ alvinr2297@gmail.com}

This is an open access article, licensed under: $\mathrm{CC}-\mathrm{BY}-\mathrm{SA}$
Abstrak: Setiap kampus atau perguruan tinggi memiliki satu layanan yang disebut bimbingan dan konseling. Peran ini dipegang oleh dosen penasehat akademik. Beban kerja dosen penasehat akademik menjadi tinggi ketika rasio jumlah dosen dan mahasiswa rendah. Untuk meringankan beban kerja dosen penasehat akademik maka dibuat sebuah sistem pakar yang dapat memudahkan mahasiswa dan dosen penasehat akademik dalam mengatasi permasalahan yang ada. Pembangunan sitem pakar ini menggunakan metode pengembangan Expert System Development Life Cycle (ESDLC). Aplikasi yang dibangunkan kemudian diujikan kepada mahasiswa Teknik Informatika di Universitas Ibnu Sina. Pengujian meliputi uji Black Box. Dari evaluasi pengguna diperoleh hasil bahwa sistem pakar yang dibangunkan dapat digunakan untuk menangani masalah-masalah seperti yang telah disimpan dalam daftar data masalah dan solusi. Tampilan estetika sistem harus diperbaiki agar pengguna tertarik untuk menggunakannya. Beberapa pengguna mengusulkan elemen multimedia dimasukkan dalam tampilan sistem pakar yang dibangunkan agar tampilannya lebih menarik.

Kata Kunci: Bimbingan dan Konseling, Faktor Kepastian, Sistem Pakar.

Student Guidance and Counseling based on Expert System Using Certainty Factor Method

Abstract: Every campus or college has one service called guidance and counseling. This role is held by the academic advisory lecturer. The workload of academic advisory lecturers becomes high when the ratio of the number of lecturers to students is low. To ease the workload of academic advisory lecturers, an expert system is made that can facilitate students and academic advisory lecturers in overcoming existing problems. The development of this expert system uses the Expert System Development Life Cycle (ESDLC) development method. The application that was developed was then tested on Informatics Engineering students at Ibn Sina University. Tests include the Black Box tests. From the evaluation of the user obtained the results that the developed expert system can be used to deal with problems such as those that have been stored in the list of problem data and solutions. The aesthetic appearance of the system must be improved in order for users to be interested in using it. Some users suggest multimedia elements be included in the developed expert system view to make it look more attractive.

Keywords: Certanty Factor, Expert Systems, Guidance and Counseling. 


\section{Pendahuluan}

Keberadaan komputer adalah salah satu bukti dari perkembangan teknologi. Banyak manfaat yang didapat dengan adanya komputer. Beberapa pekerjaan juga bisa dilakukan dengan tepat dan cepat dikarenakan beberapa aplikasi pendukung yang ada di komputer. Pada setiap kampus atau perguruan tinggi memiliki suatu layanan yang disebut bimbingan dan konseling. Bimbingan dan konseling ada yang bersifat wajib dan ada yang sifatnya tidak wajib atau dalam arti lain hanya mahasiswa yang membutuhkan bimbingan khusus yang memanfaatkan layanan ini [1]. Proses bimbingan konseling mempunyai target yang ingin dicapai, yaitu sekurang-kurangnya ditandai dengan diperolehnya pengalaman baru bagi para pelaku komunikasi khususnya pada mahasiswa yang ada di perguruan tinggi.

Seorang dosen pembimbing akademik harus memperhatikan pendekatan komunikasi interpersonal yang digunakan agar tepat sasaran dan efektif, namun pada kenyataannya dosen pembimbing akademik sering kali tidak dibekali dengan pengetahuan tentang konseling yang memadai. Hal ini disebabkan latar belakang pendidikan dosen pembimbing akademik yang beragam sehingga tidak dapat dipungkiri banyak permasalahan yang sulit untuk dipecahkan menyangkut kasus yang dialami oleh mahasiswa bimbingannya khususnya dalam masalah akademik yang dipicu oleh permalasahan non-akademik. Masalah lain dalam kegiatan pembingan akademik adalah ketidaksesuaian waktu antara dosen pembimbing akademik dengan mahasiswa sehingga sering kali proses bimbingan mengalami penundaan. Dengan adanya sistem pakar bimbingan dan konseling ini diharapkan dapat memudahkan mahasiswa dan dosen pembimbing akademik dalam proses pembimbingan akademik. Untuk mahasiswa diharapkan dengan adanya aplikasi ini membuat mahasiswa menjadi lebih menyadari peran penting dari dosen pembimbing akademik sedangkan bagi dosen pembimbing akademik diharapkan dengan adanya aplikasi ini dapat meringankan tugas dosen pembimbing akademik dalam menangani kasus bimbingan dan konseling.

Salah satu metode yang umum digunakan kebelakangan ini dalam menyelesaikan permasalahan adalah kecerdasan buatan [2]. Kecerdasan buatan terdiri atas beberapa metode antara lain jaringan syaraf tiruan [3] [4] [5], mesin pembelajaran [6] [7] [8] dan sistem pakar [9] [10]. Sistem pakar merupakan bagian dari kecerdasan buatan yang mana sistem ini bekerja dengan menggunakan pengetahuan dan metode analisis yang telah didefinisikan terlebih dahulu oleh seorang pakar yang sesuai dengan bidang keahliannya [9]. Sistem ini dibuat untuk membantu pengambilan keputusan atau pemecahan persoalan terhadap bidang yang lebih spesifik [11]. Sistem pakar merupakan alternatif penyediaan pakar terhadap masalah yang di sebabkan masih sedikitnya seorang pakar yang dapat menyelesaikan masalah tersebut. Agar bimbingan dan konseling dapat berjalan baik maka dapat digunakan sistem pakar. Selama ini sistem pakar banyak digunakan untuk penanganan penyakit baik tumbuhan, maupun penyakit manusia, tetapi sistem pakar yang kali ini akan di implementasikan terhadap permasalahan mahasiswa di Teknik Informatika Universitas Ibnu Sina, dikarenakan adanya kesamaan proses menyelesaian masalah yang menghasilkan sebuah solusi atau saran yang harus lakukan.

Pada permasalahan ini penulis menggunakan metode pemodelan data Unified Modified Language (UML) dan metode pengembangan Expert System Development Life Cycle (ESDLC).

\section{Teori Dasar}

Beberapa teori dasar dalam melaksanakan penelitian ini adalah teori tentang sistem pakar, Faktor Kepastian, Bimbingan \& Konseling

\subsection{Sistem Pakar}

Sistem pakar adalah sistem yang berusaha mengadopsi pengetahuan manusia ke komputer yang dirancang untuk memodelkan kemampuan menyelesaikan masalah seperti layaknya seorang pakar. Dengan sistem pakar ini, orang awam pun dapat menyelesaikan masalahnya atau hanya sekedar mencari suatu informasi berkualitas yang sebenarnya hanya dapat diperoleh dengan bantuan para ahli di bidangnya [9] [12].

Menurut Durkin dalam Panessai [13], komponen utama pada struktur sistem pakar meliputi basis pengetahuan, mesin inferensi, memori kerja, dan antarmuka pemakai.

\subsection{Faktor Kepastian}

Faktor Kepastian (Certainty Factor, CF) adalah teori yang digunakan untuk mengakomodasi ketidakpastian pemikiran seorang pakar [14]. Faktor Kepastian diperkenalkan oleh Shortliffe 
Buchanan dalam pembuatan MYCIN. Faktor Kepastian merupakan nilai parameter klinis yang diberikan MYCIN untuk menunjukkan besarnya kepercayaan. Dalam menghadapi suatu masalah sering ditemukan jawaban yang tidak memiliki kepastian penuh ketidakpastian ini bisa berupa probabilitas atau ke boleh jadian yang tergantung dari hasil suatu kejadian.

Hasil yang tidak pasti disebabkan oleh dua faktor yaitu aturan yang tidak pasti dan jawaban pengguna yang tidak pasti atas suatu pertanyaan yang diajukan oleh sistem. Hal ini sangat mudah dilihat pada system diagnosis penyakit, dimana pakar tidak dapat mendefinisikan tentang hubungan antara gejala dengan penyebabnya secara pasti, dan pasien tidak dapat merasakan suatu gejala dengan pasti pula. Pada akhirnya ditemukan banyak kemungkinan diagnosis [15].

Faktor Kepastian menggunakan suatu nilai untuk mengasumsikan derajat keyakinan seorang pakar terhadap suatu data. Certainty factor memperkenalkan konsep keyakinan dan ketidakyakinan yang kemudian diformulasikam kedalam rumusan dasar seperti pada Persamaan 1.

$$
\begin{aligned}
& \mathrm{CF}(\mathrm{H}, \mathrm{E})-\mathrm{MB}(\mathrm{H}, \mathrm{E})-\mathrm{MD}(\mathrm{H}, \mathrm{E}) \quad \text { Persamaan } 1 \\
& \text { Keterangan: } \\
& \mathrm{CF}(\mathrm{H}, \mathrm{E}) \text { : Certainty Factor dari hipotesis } \mathrm{H} \text { yang dipengaruhi oleh gejala (evidence) E. } \\
& \text { Besarnya CF berkisar antara -1 sampai dengan 1. Nilai -1 menunjukkan } \\
& \text { ketidakpercayaan mutlak sedangkan nilai } 1 \text { menunjukkan kepercayaan mutlak. } \\
& \mathrm{MB}(\mathrm{H}, \mathrm{E}) \text { : Ukuran kenaikan kepercayaan (measure of increased belief) terhadap hipotesis } \mathrm{H} \\
& \text { yang dipengaruhi oleh gejala } \mathrm{E} \text {. } \\
& \mathrm{MD}(\mathrm{H}, \mathrm{E}) \text { : Ukuran kenaikan ketidakpercayaan (measure of increased disbelief) terhadap } \\
& \text { hipotesis } \mathrm{H} \text { yang dipengaruhi oleh gejala } \mathrm{E} \text {. }
\end{aligned}
$$

\subsection{Bimbingan dan Konseling}

Bimbingan sebagai upaya pendidikan diartikan sebagai proses bantuan kepada individu untuk mencapai tingkat perkembangan diri secara optimum di dalam navigasi hidupnya secara mandiri. Bantuan dalam arti bimbingan yaitu memfasilitasi individu untuk mengembangkan kemampuan memilih dan mengambil keputusan atas tanggung jawab sendiri. Kondisi perkembangan optimum adalah kondisi dinamis yang ditandai dengan kesiapan dan kemampuan individu untuk memperbaiki diri (self-improvement) agar dia menjadi pribadi yang berfungsi penuh (fully-fungctioning) di dalam lingkungannya [16].

Bimbingan adalah suatu proses pemberian bantuan kepada individu secara berkelanjutan dan sistematis, yang dilakukan oleh seorang ahli yang telah mendapat latihan khusus untuk itu, dimaksudkan agar individu dapat memahami dirinya, lingkunganya serta dapat mengarahkan diri dan menyesuaikan diri dengan lingkungan untuk dapat mengembangkan potensi dirinya secara optimal untuk kesejahteraan dirinya dan kesejahteraan masyarakat [17]. Sedangkan konseling adalah proses bantuan yang dalam sejumlah literature dipandang sebagai jantung bimbingan (counseling is the heart of guidance) karena bantuan konseling lebih langsung bersentuhan dengan masalah individu secara individual dan kelompok [18].

Konseling merupakan upaya membantu individu melalui proses interaksi yang bersifat pribadi antara konselor dan konseli mampu memahami diri dan lingkungannya, mampu membuat keputusan dan menentukan tujuan berdasarkan nilai yang diyakininya sehingga konseli merasa bahagia dan efektif perilakunya [19].

Bimbingan sangat penting dalam menunjang keberhasilan proses belajar mengajar [20] [21] [22] [23] [24]. Bahkan saat dalam kelas [25] [26]. Demikian halnya dnegan konseling. Melalui konseling masalah-masalah yang menghalangi keberhasilan proses belajar dan mengajar bisa diminimalkan [27] [28] [29] [30].

\section{Metodologi}

Umumnya langkah-langkah dalam penelitian terdiri atas studi pustaka, identifikasi masalah, pengumpulan data, pengolahan data, perancangan sistem, dan implementasi sistem [31] [32] [33]. Langkah-langkah penelitian dalam penelitian ini dapat dilihat pada Gambar 1. 


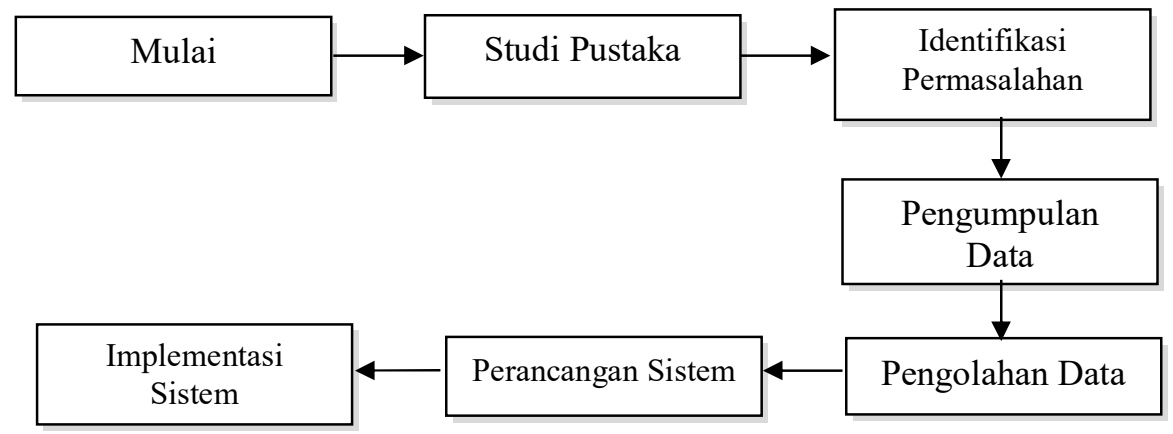

Gambar 1. Kerangka Pemecahan Masalah

\subsection{Metode Pembangunan Sistem Pakar}

Metode yang digunakan dalam pembangunan sistem pakar dalam penelitian ini adalah Expert System Development Life Cycle (ESDLC). Metode ESDLC memiliki enam tahapan aktifitas yaitu penilaian, akuisisisi pengetahuan, desain, pengujian, dokumentasi, pemeliharaan.

Metode penelitian menggunakan metode Expert System Development Life Cycle (ESDLC) untuk menggambarkan rincian tahapan pembuatan.

1. Penilaian (Assessment)

Merupakan proses untuk menentukan kelayakan dan justifikasi atas permasalahan yang akandiambil. Setelah proyek pengembangan dianggap layak dan sesuai dengan tujuan, maka selanjutnya ditentukan fitur-fitur penting dan ruang lingkup proyek serta sumber daya yang dibutuhkan. Sumber pengetahuan yang diperlukan diidentifikasi dan ditentukan persyaratan-persyaratan proyek.

2. Akuisisisi Pengetahuan (Knowlage Acquisition)

Merupakan proses untuk mendapatkan pengetahuan tentang permasalahan yang akan dibahas dan digunakan sebagai panduan dalam pengembangan. Pengetahuan ini digunakan untukmemberikan informasi tentang permasalahan yang menjadi bahan acuan dalam mendesain sistem pakar. Tahap ini meliputi studi dengan diadakannya pertemuan dengan pakar untuk membahas aspek dari permasalahan.

3. Desain

Berdasarkan pengetahuan yang telah didapatkan dalam proses Akuisisi pengetahuan, maka desain antarmuka maupun teknik penyelesaian masalah dapat diimplementasikan ke dalam sistem pakar. Dalam tahap desain ini, seluruh struktur dan organisasi dari pengetahuan harus ditetapkan dan dapat direpresentasikan kedalam sistem. Pada tahap desain, sebuah system prototype di bangun. Tujuan dari pembangunan prototype tersebut adalah untuk memberikan pemahaman yang lebih baik atas masalah.

4. Pengujian

Tahap ini dimaksudkan untuk menguji apakah sistem pakar yang dibangun telah sesuai dengan tujuan pengembangan maupun kesesuaian kinerja sistem dengan metode penyelesaianmasalah yang bersumber dari pengetahuan yang sudah didapkan. Apabila dalam tahap ini terdapat bagian yang harus dievaluasi maupun dimodifikasi maka hal tersebut harus segera dilakukan agar sistem pakar dapat berfungsi sebagaimana tujuan pengembangannya.

5. Dokumentasi

Tahap dokumentasi diperlukan untuk mengkompilasi semua informasi proyek sistem pakar ke dalam bentuk dokumen yang dapat memenuhi persyaratan yang dibutuhkan pengguna dan pengembang sistem. Dokumentasi tersebut menjelaskan tentang bagaimana mengoperasikan sistem, instalasi, kebutuhan minimum sistem maupun bantuan yang mungkin diperlukan oleh pengguna maupun pengembang sistem pakar. Selain hal tersebut, maka secara khusus harus juga mendokumentasikan kamus data pengetahuan maupun prosedur penelusuran masalah dalam mesin inferensinya.

6. Pemeliharaan

Setelah sistem digunakan dalam lingkungan kerja, maka selanjutnya diperlukan 
pemeliharaan secara berkala. Pengetahuan itu sifatnya tidak statis melainkan terus tumbuh dan berkembang. Pengetahuan dari sistem perlu diperbaharui atau disempurnakan untuk memenuhi kebutuhan saat ini.

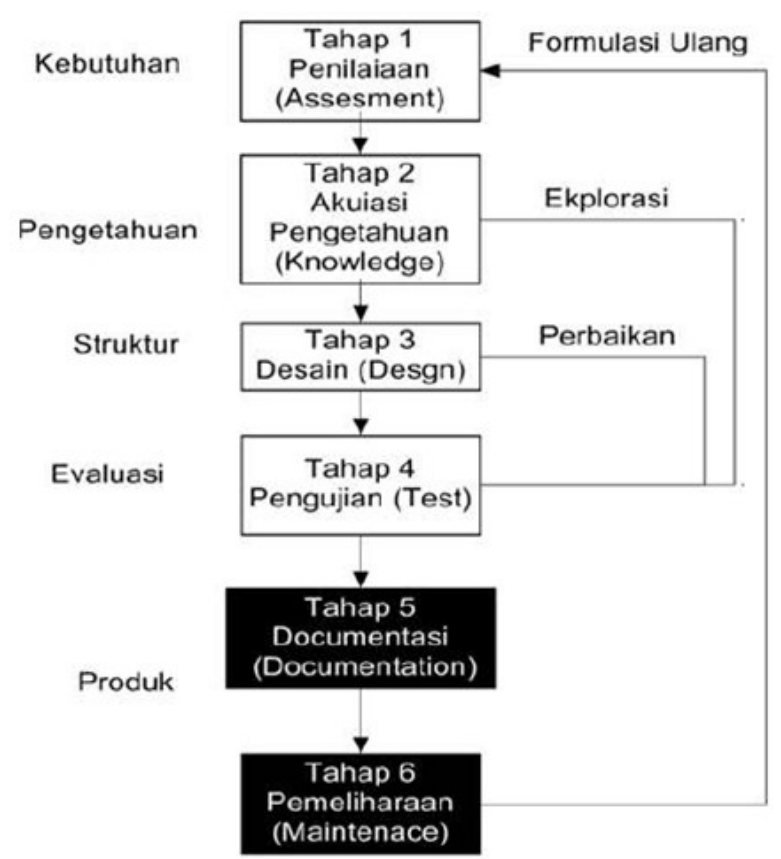

Gambar 2. Metode Pengembangan ESDLC [11]

\subsection{Elemen Grafis Rancangan Sistem}

Hasil rancangan sistem yang dibangun kemudian divisualisasikan dan didokumentasikan menggunakan UML (Unified Modeling Language). Elemen grafis UML dari sistem terdiri atas Activity Diagram, Use Case Diagram, Sequence Diagram dan Class Diagram.

\section{Activity Diagram}

Gambar 3 menggambarkan rangkaian aktivitas admin untuk memproses data pada sistem pakar bimbingan dan konseling mahasiswa dari mulai sampai selesai.

\section{Use Case Diagram}

Gambar 4 Menggambarkan use case diagram sistem pakar bimbingan dan konseling mahasiswa dimana aplikasi memiliki dua aktor yaitu pengguna dan admin.

\section{Sequence Diagram}

Gambar 5 menggambarkan proses pengolahan data dimana aktor yaitu admin membuka halaman utama. lalu pada menu pilihan admin memproses data dengan menu edit, tambah atau hapus. Setelah berhasil makan data akan tersimpan di database.

\section{Class Diagram}

Gambar 6 menggambarkan class diagram pada sistem pakar bimbingan dan konseling mahasiswa di Universitas Ibnu Sina. 

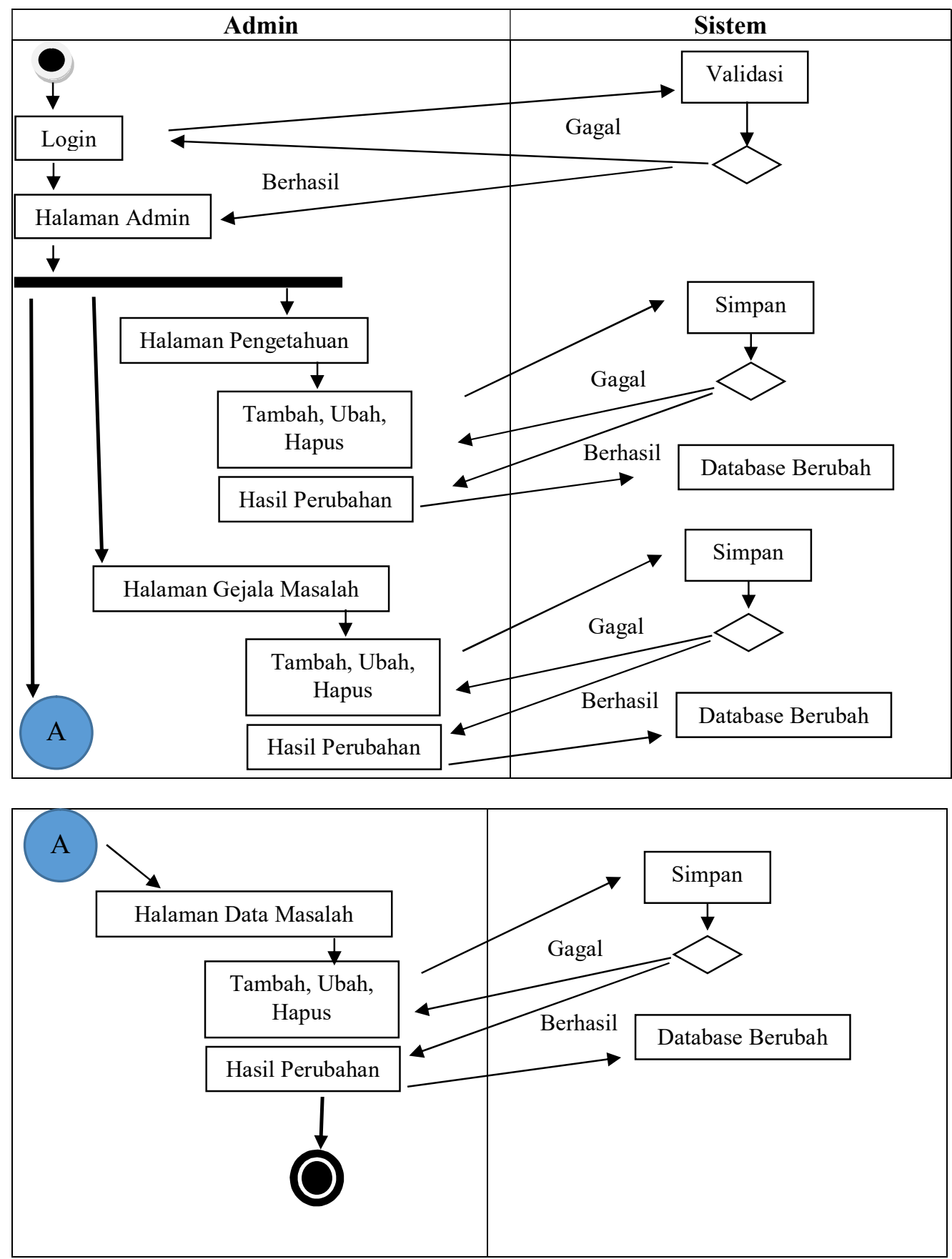

Gambar 3. Activity Diagram 


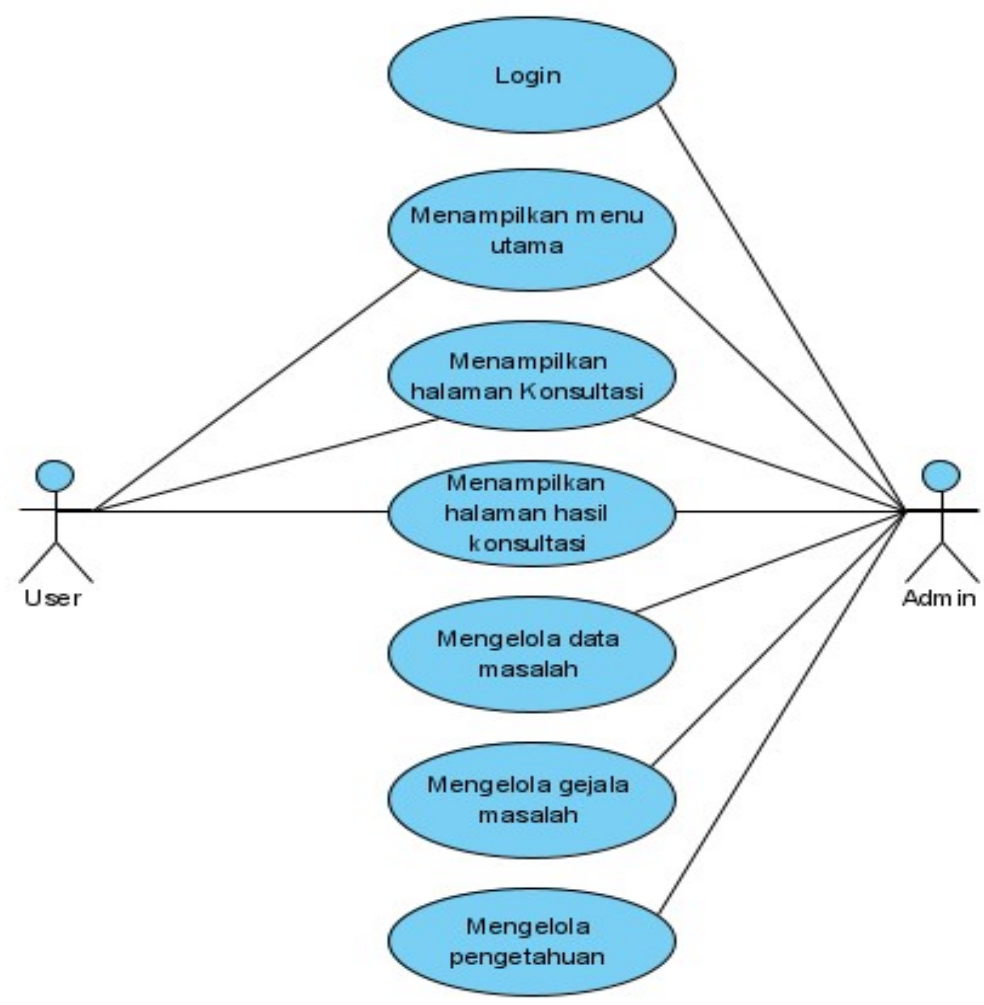

Gambar 4. Use Case Diagram

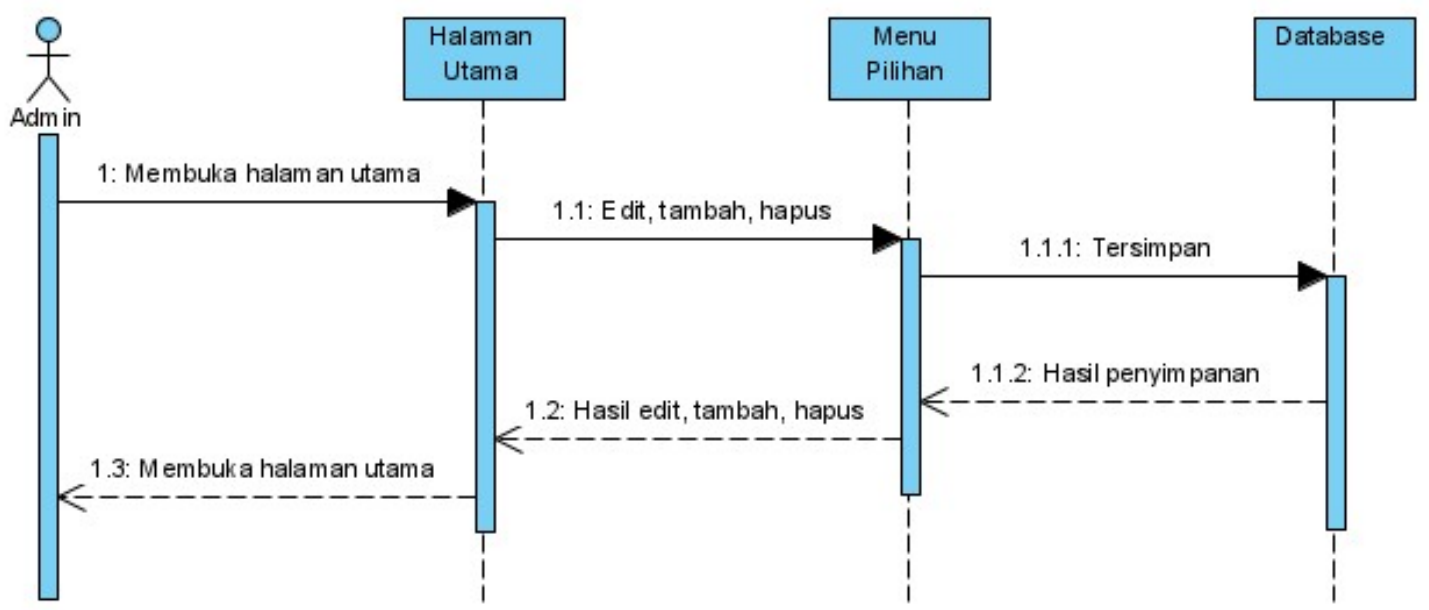

Gambar 5. Sequence Diagram 


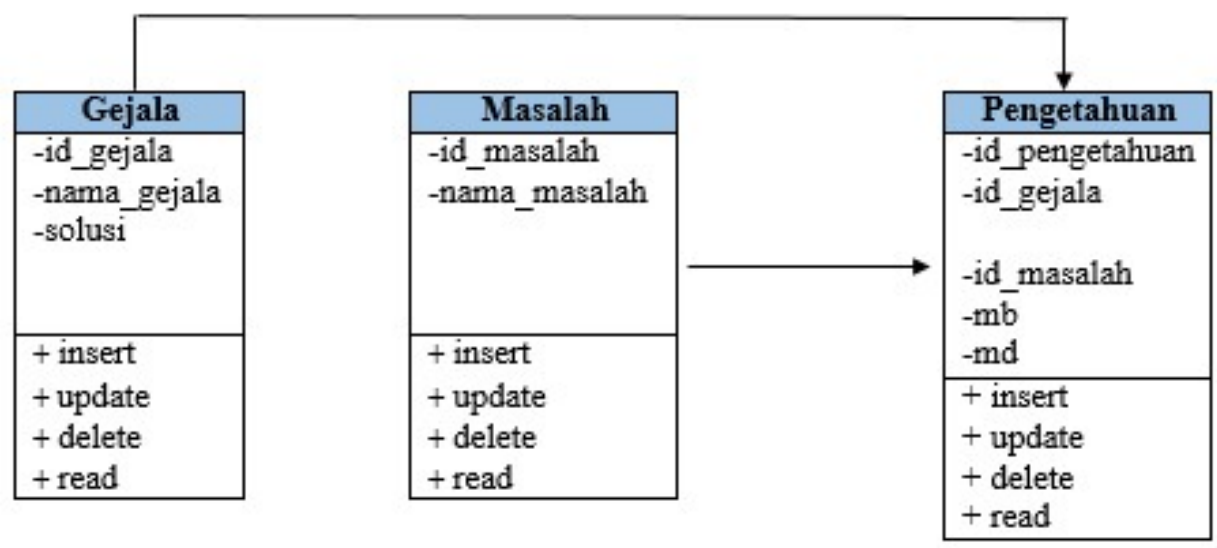

Gambar 6. Class Diagram

\subsection{Daftar Data}

3.3.1. Data Masalah

Tabel 1 adalah tabel data masalah yang berisikan nomor id masalah, nama masalah, dan solusi.

Tabel 1. Data Masalah

\begin{tabular}{|c|c|c|}
\hline ID Masalah & Nama Masalah & Solusi \\
\hline P01 & Bolos & $\begin{array}{l}\text { Bangunlah komunikasi yang baik agar mahasiswa } \\
\text { tersebut merasa diperhatikan sehingga mahasiswa } \\
\text { tersebut tidak akan bolos dalam pelajaran lagi. }\end{array}$ \\
\hline $\mathrm{P} 02$ & Malas & $\begin{array}{l}\text { Bangunlah metode belajar yang efektif dan berilah } \\
\text { motivasi semangat belajar agar dalam pembelajaran } \\
\text { mahasiswa tidak merasa bosan dan terhindar dari } \\
\text { malasnya belajar. }\end{array}$ \\
\hline P03 & Berkelahi & $\begin{array}{l}\text { Mempertemukan mahasiswa yang berkelahi dan minta } \\
\text { penjelasan dari ke dua mahasiswa tersebut, setelah itu } \\
\text { berilah mereka nasehat mana yang baik dan mana yang } \\
\text { buruk. Karena hanya menimbulkan dampak negatif } \\
\text { saja. }\end{array}$ \\
\hline P05 & Menyontek & $\begin{array}{l}\text { Memuji hasil usaha terbaik walaupun nilai belum } \\
\text { memenuhi standar dan berikan tugas latihan untuk } \\
\text { menjawab soal. }\end{array}$ \\
\hline P07 & Gangguan Emosional & $\begin{array}{l}\text { Mencari akar penyebabnya dan membantu agar } \\
\text { mahasiswa tersebut merasa tenang dan tidak selalu } \\
\text { merasa cemas yang dapat membuat mahasiswa } \\
\text { tersebut merasa bersalah. }\end{array}$ \\
\hline ID Masalah & Nama Masalah & Solusi \\
\hline P010 & $\begin{array}{l}\text { Kesulitan Belajar } \\
\text { Pada Bidang } \\
\text { Tertentu }\end{array}$ & $\begin{array}{l}\text { Ajak mahasiswa aktif berpartisipasi dalam kegiatan } \\
\text { belajar dan seorang dosen harus aktif memberi } \\
\text { pertanyaan kepada mahasiswa dan menanyakan apa } \\
\text { saja yang belum di pahami oleh mahasiswa. }\end{array}$ \\
\hline P011 & $\begin{array}{c}\text { Merokok Di } \\
\text { Lingkungan Kampus }\end{array}$ & $\begin{array}{l}\text { Memberikan edukasi dari bahaya nya merokok dan } \\
\text { melarang mahasiswa tersebut dengan cara lembut tapi } \\
\text { tegas. }\end{array}$ \\
\hline
\end{tabular}




\subsubsection{Daftar Data Gejala Masalah}

Tabel 2 adalah tabel data gejala masalah yang berisikan nomor id gejala dan nama gejala.

Tabel 2. Data Gejala Masalah

\begin{tabular}{|c|c|}
\hline $\begin{array}{c}\text { ID } \\
\text { Gejala }\end{array}$ & Nama Gejala \\
\hline Q01 & Memiliki pergaulan yang bebas tanpa ada bimbingan orang tua \\
\hline Q02 & Sering mengikuti dan melakukan perbuatan teman \\
\hline Q03 & Merasa dijauhi oleh teman sehingga tidak mau sekolah \\
\hline Q04 & Selalu dicurigai dan dimusuhi teman \\
\hline Q05 & Terlambat ke kampus karena mendapat tugas dari orang tua \\
\hline Q06 & Kesulitan dalam memahami mata pelajaran tertentu \\
\hline Q07 & Tidak memiliki motivasi belajar dari orang terdekat atau diri sendiri \\
\hline Q08 & Merasa sarana dan prasarana perkuliahan kurang lengkap dan memadai \\
\hline Q09 & Saling melemparkan ejekan \\
\hline Q10 & Memiliki pertengkaran pribadi atau kelompok \\
\hline Q11 & Memiliki permasalahan seputar teman perempuan atau pacar \\
\hline Q12 & Merasa direndahkan dan diacuhkan \\
\hline Q13 & Sering mengalami kekecewaan dan frustasi \\
\hline Q14 & Terpengaruh dengan permasalahan yang sedang dihadapi keluarga \\
\hline Q15 & Merasa masalah keluarga sudah mempengaruhi terlalu berat \\
\hline Q16 & Mengerjakan soal selalu merasa kurang mampu untuk menjawabnya \\
\hline Q17 & Merasa kurangnya sarana dan prasarana membuat menguasai mata kuliah tertentu \\
\hline Q18 & Bermasalah dengan kepercayaan diri dan mental \\
\hline Q19 & Memiliki potensi yang terbatas \\
\hline Q20 & Mengalami kesulitan mendapatkan transportasi \\
\hline Q21 & Sering Ketiduran \\
\hline Q22 & Bermasalah dengan tanggung jawab yang diterima \\
\hline Q23 & Mendapatkan lembur pekerjaan \\
\hline Q24 & Memiliki masalah dengan diri sendiri, teman atau keluarga \\
\hline Q25 & Merasa tidak Nyaman dalam kondisi apapun karena terpengaruh keadaan keluarga \\
\hline Q26 & Memiliki sifat tidak sabaran, tempramen dan sering terpengaruh \\
\hline Q27 & Merasa hal yang dilakukan karena keterpaksaan ekonomi \\
\hline Q28 & Kurang mendapatkan perhatian dari orang tua \\
\hline Q29 & Memiliki sifat iri terhadap teman atau orang sekitar \\
\hline Q30 & Mengalami permasalahan pribadi yang berat \\
\hline Q31 & Mempunyai masalah keluarga yang membuat hidup putus asa \\
\hline Q32 & Lemahnya iman dan jauh dari ajaran agama \\
\hline Q33 & Kurang menyukai dosen atau asisten dosen dari mata kuliah tertentu \\
\hline Q34 & Memiliki mata kuliah yang tidak disukai atau dikuasai \\
\hline Q35 & Memiliki potensi dan bakat yang diketahui \\
\hline $\begin{array}{c}\text { ID } \\
\text { Gejala }\end{array}$ & Nama Gejala \\
\hline Q36 & Mengalamai penurunan prestasi belajar \\
\hline Q37 & Sering terlambat masuk kuliah \\
\hline Q38 & Kebiasaan di luar kampus \\
\hline Q39 & Kurangnya pemantauan di lingkungan kampus (cctv) \\
\hline Q40 & Kurangnya kesadaran hidup sehat \\
\hline
\end{tabular}




\subsubsection{Tabel Data Pengetahuan}

Tabel 3 berisi nama masalah, nama gejala, ukuran kenaikan kepercayaan dan ukuran kenaikan ketidak percayaan.

Tabel 3. Data Pengetahuan

\begin{tabular}{|c|c|c|c|c|}
\hline No & $\begin{array}{c}\text { Nama } \\
\text { Masalah }\end{array}$ & Nama Gejala & MB & MD \\
\hline \multirow{5}{*}{1} & \multirow{5}{*}{ Bolos } & $\begin{array}{l}\text { Memiliki pergaulan yang bebas tanpa ada bimbingan } \\
\text { orang tua }\end{array}$ & 0.76 & 0.24 \\
\hline & & Sering mengikuti dan melakukan perbuatan teman & 0.76 & 0.24 \\
\hline & & Merasa dijauhi oleh teman sehingga tidak mau sekolah & 0.59 & 0.41 \\
\hline & & Selalu dicurigai dan dimusuhi teman & 0.65 & 0.35 \\
\hline & & $\begin{array}{l}\text { Terlambat masuk karena mendapat tugas dari orang tua } \\
\text { / kantor }\end{array}$ & 0.71 & 0.29 \\
\hline \multirow{3}{*}{2} & \multirow{3}{*}{ Malas } & Kesulitan dalam memahami mata pelajaran tertentu & 0.71 & 0.29 \\
\hline & & $\begin{array}{l}\text { Tidak memiliki motivasi belajar dari orang terdekat } \\
\text { atau diri sendiri }\end{array}$ & 0.76 & 0.24 \\
\hline & & $\begin{array}{l}\text { Merasa sarana dan prasarana perkuliahan yang kurang } \\
\text { lengkap dan memadai }\end{array}$ & 0.65 & 0.35 \\
\hline \multirow{4}{*}{3} & \multirow{4}{*}{ Berkelahi } & Saling melemparkan ejekan & 0.71 & 0.29 \\
\hline & & Memiliki pertengkaran pribadi atau kelompok & 0.76 & 0.24 \\
\hline & & $\begin{array}{l}\text { Memiliki permasalahan seputar teman perempuan atau } \\
\text { pacar }\end{array}$ & 0.76 & 0.24 \\
\hline & & Merasa direndahkan dan diacuhkan & 0.71 & 0.29 \\
\hline \multirow{4}{*}{4} & \multirow{4}{*}{ Menyontek } & $\begin{array}{l}\text { Mengerjakan soal selalu merasa kurang mampu untuk } \\
\text { menjawabnya }\end{array}$ & 0.76 & 0.24 \\
\hline & & $\begin{array}{l}\text { Merasa kurangnya sarana dan prasarana membuat } \\
\text { menguasai mata kuliah tertentu }\end{array}$ & 0.65 & 0.35 \\
\hline & & Bermasalah dengan kepercayaan diri dan mental & 0.76 & 0.24 \\
\hline & & Memiliki potensi yang terbatas & 0.88 & 0.12 \\
\hline
\end{tabular}

\begin{tabular}{|c|c|c|c|c|}
\hline No & $\begin{array}{c}\text { Nama } \\
\text { Masalah }\end{array}$ & Nama Gejala & MB & MD \\
\hline \multirow{3}{*}{5} & \multirow{3}{*}{$\begin{array}{l}\text { Gangguan } \\
\text { Emosional }\end{array}$} & $\begin{array}{l}\text { Memiliki masalah dengan diri sendiri, teman atau } \\
\text { keluarga }\end{array}$ & 0.76 & 0.24 \\
\hline & & $\begin{array}{l}\text { Merasa tidak nyaman dalam kondisi apapun karena } \\
\text { terpengaruh keadaan keluarga }\end{array}$ & 0.59 & 0.41 \\
\hline & & $\begin{array}{l}\text { Memiliki sifat tidak sabaran, tempramen dan sering } \\
\text { terpengaruh }\end{array}$ & 0.71 & 0.29 \\
\hline \multirow{4}{*}{6} & \multirow{4}{*}{$\begin{array}{c}\text { Kesulitan } \\
\text { Belajar pada } \\
\text { Bidang } \\
\text { Tertentu }\end{array}$} & $\begin{array}{l}\text { Kurang menyukai dosen atau asisten dosen dari } \\
\text { mata kuliah tertentu }\end{array}$ & 0.76 & 0.24 \\
\hline & & Memiliki mata kuliah yang tidak disukai & 0.71 & 0.29 \\
\hline & & Memiliki potensi dan bakat yang diketahui & 0.88 & 0.12 \\
\hline & & Sering terlambat masuk kuliah & 0.59 & 0.41 \\
\hline \multirow{3}{*}{7} & \multirow{3}{*}{$\begin{array}{l}\text { Merokok Di } \\
\text { lingkungan } \\
\text { kampus }\end{array}$} & Kebiasaan di luar kampus & 0.59 & 0.41 \\
\hline & & $\begin{array}{l}\text { Kurangnya pemantauan di lingkungan kampus } \\
\text { (CCTV) }\end{array}$ & 0.71 & 0.29 \\
\hline & & Kurangnya kesadaran hidup sehat & 0.76 & 0.24 \\
\hline
\end{tabular}




\section{Hasil dan Analisa}

\subsection{Tampilan Sistem}

Tampilan Halaman Menu Utama ditunjukkan pada Gambar 7, tampilan halaman Konsultasi Permasalahan ditunjukkan pada Gambar 8, dan tampilan halaman Hasil Konsultasi ditunjukkan pada Gambar 9.

\section{Selamat Datang!}

Sistem Pakar Bimbingan dan Konseling Mahasiswa Teknik Informatika Universitas Ibnu Sina

Gambar 7. Halaman Menu Utama

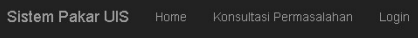

Sistem Pakar Bimbingan dan Konseling Mahasiswa Teknik Informatika

Gambar 8. Halaman Konsultasi Permasalahan

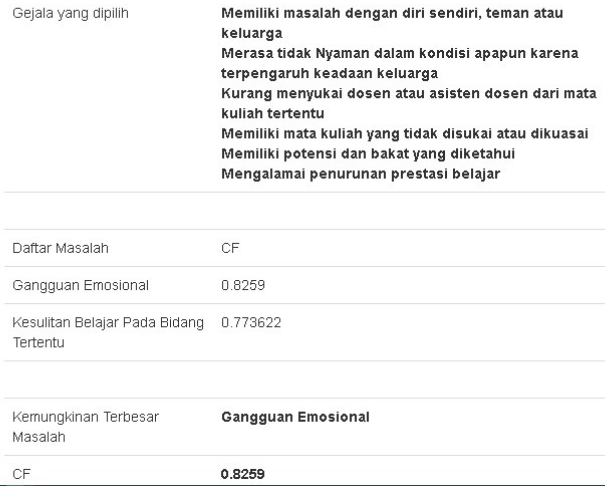

Gambar 9. Halaman Hasil Konsultasi 


\subsection{Hasil Pengujian}

Hasil pengujian black box dapat dilihat pada Tabel 4.

Tabel 4. Pengujian Black Box

\begin{tabular}{|c|c|c|c|c|}
\hline No & Masukan & Proses & Keluaran & Hasil \\
\hline 1 & Halaman Index & $\begin{array}{l}\text { http://localhost/sp_uis/inde } \\
\text { x.php }\end{array}$ & $\begin{array}{l}\text { Tampil halaman index sesuai } \\
\text { Pengguna }\end{array}$ & Sesuai \\
\hline 2 & Halaman Home & $\begin{array}{l}\text { http://localhost/sp_uis/hom } \\
\text { e.php }\end{array}$ & $\begin{array}{l}\text { Tampil halaman home sesuai } \\
\text { pengguna }\end{array}$ & Sesuai \\
\hline 3 & $\begin{array}{l}\text { Halaman } \\
\text { Konsultasi }\end{array}$ & $\begin{array}{l}\text { http://localhost/sp_uis/cf- } \\
\text { php-mysql.php }\end{array}$ & $\begin{array}{l}\text { Tampil halaman konsultasi } \\
\text { dengan hak akses pengguna }\end{array}$ & Sesuai \\
\hline 4 & $\begin{array}{l}\text { Halaman Login } \\
\text { Admin }\end{array}$ & $\begin{array}{l}\text { http://localhost/sp_uis/login } \\
\text {.php }\end{array}$ & $\begin{array}{l}\text { Tampil halaman login sesuai } \\
\text { pengguna }\end{array}$ & Sesuai \\
\hline 5 & $\begin{array}{l}\text { Halaman Utama } \\
\text { Admin }\end{array}$ & $\begin{array}{l}\text { http://localhost/sp_uis/admi } \\
\text { n.php }\end{array}$ & $\begin{array}{l}\text { Tampil halaman utama } \\
\text { admin sesuai pengguna }\end{array}$ & Sesuai \\
\hline 6 & $\begin{array}{l}\text { Halaman Data } \\
\text { Masalah }\end{array}$ & $\begin{array}{l}\text { http://localhost/sp_uis/masa } \\
\text { lah.php }\end{array}$ & $\begin{array}{l}\text { Tampil halaman data } \\
\text { masalah dengan hak akses } \\
\text { pengguna. }\end{array}$ & Sesuai \\
\hline 7 & $\begin{array}{l}\text { Halaman Gejala } \\
\text { Masalah }\end{array}$ & $\begin{array}{l}\text { http://localhost/sp_uis/gejal } \\
\text { a.php }\end{array}$ & $\begin{array}{l}\text { Tampil halaman gejala } \\
\text { masalah sesuai hak akses } \\
\text { pengguna }\end{array}$ & Sesuai \\
\hline 8 & $\begin{array}{l}\text { Halaman Data } \\
\text { Pengetahuan }\end{array}$ & $\begin{array}{l}\text { http://localhost/sp_uis/peng } \\
\text { etahuan.php }\end{array}$ & $\begin{array}{l}\text { Tampil halaman data } \\
\text { pengetahuan sesuai hak akses } \\
\text { pengguna }\end{array}$ & Sesuai \\
\hline
\end{tabular}

\subsection{Analisa Hasil}

Berdasarkan hasil pengujian black box (Tabel 4), disimpulkan bahwa sistem yang dibangun berjalan seperti yang diharapkan. Sistem pakar dapat digunakan untuk menangani masalah-masalah seperti yang telah disimpan dalam daftar data masalah dan solusi.

Berdasarkan keterangan responden, pengguna menyatakan bahwa tampilan sistem monoton dan tidak menarik. Tampilan ringkas dan hanya terdiri dari informasi membuat pengguna tidak tertarik untuk menggunakannya.

Umumnya pengguna berpendapat bahwa warna latar belakang dan ukuran huruf perlu diperhatikan dalam sistem pakar yang dibangunkan ini. Selain itu, beberapa pengguna berpikir bahwa sistem pakar ini akan lebih menarik jika dimasukkan unsur-unsur multimedia dalam halamannya.

\section{Kesimpulan}

Selain informasi penting yang disajikan, faktor estetika juga harus dipertimbangkan. Faktor estetika penting dalam pembangunan sebuah sistem agar pengguna tertarik untuk menggunakannya. Estetika yang dimaksudkan bisa berupa penggunaan warna latar belakang, warna huruf, dan ukuran huruf. Penggunaan multimedia dalam tampilan halaman perlu utnuk menarik minat pengguna.

\section{Daftar Pustaka}

[1] A. Anna, and R. Arissusandi, "Rancang Bangun Sistem Informasi Akuntansi Laporan Laba Rugi Berbasis Web Pada PT. United Tractors Pontianak", EVOLUSI: Jurnal Sains dan Manajemen, vol. 7, no. 2, pp. 6-14, September 2019. 
[2] A. C. D and S. K. G, "A Comprehensive Review on Artificial Intelligence Techniques for Covid-19 Pandemic", International Journal of Artificial Intelligence, vol. 8, no. 1, pp. 17-24, Jun. 2021. doi: 10.36079/lamintang.ijai-0801.193

[3] S. S. R, V. Desai, M. Singh, and K. M, "Survey on Early Detection of Alzhiemer's Disease Using Capsule Neural Network", International Journal of Artificial Intelligence, vol. 7, no. 1, pp. 7-12, Apr. 2020. doi: 10.36079/lamintang.ijai-0701.65

[4] D. Kamath, M. F. Fathima, K. P. Monica, and M. Kusuma, "Survey on Early Detection of Alzheimer's Disease using Different Types of Neural Network Architecture", International Journal of Artificial Intelligence, vol. 8, no. 1, pp. 25-32, Jun. 2021. doi: 10.36079/lamintang ijai-0801.217

[5] A. M. J., B. B., J. G., and K. Mohanchandra, "Brain Computer Interface for Emergency Virtual Voice", International Journal of Artificial Intelligence, vol. 8, no. 1, pp. 40-47, Jun. 2021. doi: 10.36079/lamintang.ijai-0801.222

[6] S. Anderson and A. Lawi, "Indonesia Network Infrastructures and Workforce Adequacy to Implement Machine Learning for Large-Scale Manufacturing", International Journal of Artificial Intelligence, vol. 8, no. 1, pp. 1-16, Jun. 2021. doi: 10.36079/lamintang lamintang.ijai-0801.182

[7] I. Y. Panessai, M. M. Lakulu, M. H. Abdul Rahman, N. A. Z. Mohd Noor, N. S. Mat Salleh, and Aldrin Aran Bilong, "PSAP: Improving Accuracy of Students' Final Grade Prediction using ID3 and C4.5", International Journal of Artificial Intelligence, vol. 6, no. 2, pp. 125 133, Dec. 2019. doi: 10.36079/lamintang lamintang.ijai-0602.42

[8] I. Y. Panessai, M. M. Lakulu, M. H. Abdul Rahman, N. A. Z. Mohd Noor, N. S. Mat Salleh, N. Iksan, R. M. Rasli, M. R. Husin, H. Ahmad, A. A. Ariffin, S. A., A. Alias, S. K. Subramaniam, S. Majid, M. A. Bora, A. A. Bilong, \& N. M. Mazli, "Predicting Students' Academic Performance: A Review for the Attribute Used," International Journal of Academic Research in Business and Social Sciences, vol. 11, no. 4, pp. 595-603, 2021.

[9] A. P. Dicki Alamsyah and Normalisa, "Sistem Pakar Diagnosa Penyakit Ginjal", International Journal of Artificial Intelligence, vol. 6, no. 1, pp. 53 - 74, Sep. 2019. doi: 10.36079/lamintang.ijai-0601.32

[10] I. Y. Panessai, “Arsitektur Sistem Pakar: Pengenalan Sistem Pakar”, 2021. [Online]. Available: osf.io/8nhwx. doi: 10.31219/osf.io/8nhwx. [Accessed: August] 202.

[11] I. Y. Panessai, "Arsitektur Sistem Pakar: Konsep Sistem Pakar", 2021. [Online]. Available: osf.io/h7t3r. doi: 10.31219/osf.io/h7t3r. [Accessed: August 2021].

[12] I. Y. Panessai, Arsitektur Sistem Pakar: Pengenalan Sistem Pakar. Batam: Lamintang, 2021. doi: 10.31219/osf.io/8nhwx. [Accessed: August 2021].

[13] I. Y. Panessai, Arsitektur Sistem Pakar: Konsep Sistem Pakar. Batam: Lamintang, 2021. doi: 10.31219/osf.io/h7t3r

[14] R. Agusli, S. Sutarman, \& S. Suhendri, "Sistem Pakar Identifikasi Tipe Kepribadian Karyawan Menggunakan Metode Certainty Factor," Jurnal Sisfotek Global, vol. 7, no. 1, pp. 21-27, Maret. 2017.

[15] H. T. Sihotang, "Pembuatan Aplikasi E-Learning Pada SMK Swasta Pariwisata Imelda", Jurnal Mantik Penusa, vol. 1, no. 2, pp. 70-75, Des. 2017.

[16] C. P. Bhakti, "Program bimbingan dan konseling komprehensif untuk mengembangkan standar kompetensi siswa", JURKAM: Jurnal Konseling Andi Matappa, vol. 1, no. 2, pp. 131-141, Feb. 2017.

[17] H. A. Hanan, "Meningkatkan Motivasi Belajar Bimbingan konseling Siswa Kelas VIII. C Melalui Bimbingan Kelompok Semester Satu Tahun Pelajaran 2015/2016", Jurnal Ilmiah Mandala Education, vol. 3, no. 1, pp. 62-72, April 2017.

[18] B. A. Habsy, "Filosofi Ilmu Bimbingan dan Konseling Indonesia", Jurnal Pendidikan (Teori dan Praktik), vol. 2, no. 1, pp. 1-11, 2017.

[19] S. Suprihatin, "Kompetensi Profesional Guru Bimbingan dan Konseling Dalam Pelayanan Bimbingan dan Konseling," JIGC (Journal of Islamic Guidance and Counseling), vol. 1, no. 1, pp. 14-26, Des 2017.

[20] Nur Syazlina Hanim, "Pelajar Berkecerdasan Tinggi dalam Kalangan Pelajar Kelas Rancangan Khas", International Journal of Humanities, Management and Social Science, vol. 2, no. 1, pp. 1 - 13, Jun. 2019. doi: 10.36079/lamintang.ij-humass-0201.19 
[21] N. Laili, S. E. Purwanto, and F. Alyani, "Pengaruh Model Penemuan Terbimbing Berbantu LKPD terhadap Kemampuan Pemahaman Konsep Matematis Siswa SMPN 6 Depok", International Journal of Humanities, Management and Social Science, vol. 2, no. 1, pp. 14 - 37, Jun. 2019. doi: 10.36079/lamintang.ij-humass-0201.20

[22] R. Hashim and M. H. Mohamad Yatim, "Hubungan Antara Motivasi dan Penerimaan Dengan Pencapaian Akademik Pelajar Dalam Pembelajaran Menggunakan M-Pembelajaran di Kolej Vokasional", International Journal of Humanities, Management and Social Science, vol. 2, no. 2, pp. 89 - 94, Dec. 2019. doi: 10.36079/lamintang.ij-humass-0202.37

[23] N. Laili, "Hubungan Adversity Quotient dan Hasil Belajar Matematika Peserta Didik dalam Pembelajaran Jarak Jauh di SMP”, Journal of Humanities and Social Science, vol. 3, no. 1, pp. 33-39, Apr. 2021. doi: 10.36079/lamintang.jhass-0301.210

[24] M. R. Husin, "Perspektif Guru Terhadap Pembelajaran Pelajar Remaja", Journal of Humanities and Social Science, vol. 3, no. 1, pp. 40-49, Apr. 2021. doi: 10.36079/lamintang.jhass-0301.211

[25] H. Ariffin and L. F. Md Ibharim, "Aplikasi Kahoot Sebagai Alat Pengujian Terhadap Pencapaian Murid dalam Mata Pelajaran Sejarah”, International Journal of Education, Science, Technology, and Engineering, vol. 2, no. 2, pp. 90 - 96, Dec. 2019. doi: 10.36079/lamintang.ijeste-0202.44

[26] M. F. Mohd Baharan, N. Mohsin, Mohd Nor Mamat, and Z. Temyati, "Penggunaan Sistem Persekitaran Pembelajaran Maya Frog di Sekolah-Sekolah Malaysia: Pengalaman dan Prospek Masa Depan”, International Journal of Education, Science, Technology, and Engineering, vol. 2, no. 2, pp. 84 - 89, Dec. 2019. doi: 10.36079/lamintang.ijeste-0202.43

[27] Lukman Hakim bin Mohamad Amin, "Masalah Kecelaruan Tingkah Laku: Ponteng Sekolah", International Journal of Humanities, Management and Social Science, vol. 2, no. 1, pp. 51 - 64, Jun. 2019. doi: 10.36079/lamintang.ij-humass-0201.22

[28] Ngo Yew Yung, "Gejala Buli Secara Fizikal yang Semakin Berleluasa di Sekolah", International Journal of Humanities, Management and Social Science, vol. 2, no. 1, pp. 65 - 75, Jun. 2019. doi: 10.36079/lamintang.ij-humass-0201.24

[29] Nur Najwa Solehah Binti Hasan Ashaari, S. N. Sumadi, N. A. Salleh, N. I. Ismail, N. A. H. Adenan, and M. R. Husin, "Masalah Pergaulan Bebas dalam Kalangan Remaja Sekolah", International Journal of Humanities, Management and Social Science, vol. 2, no. 1, pp. 38 - 50, Jun. 2019. doi: 10.36079/lamintang.ij-humass-0201.21

[30] M. Farhan, "Masalah Pembelajaran untuk Pelajar Pendidikan Khas: Dana dan Prasarana", International Journal of Humanities, Management and Social Science, vol. 3, no. 1, pp. 1-10, Jun. 2020. doi: 10.36079/lamintang.ij-humass-0301.106

[31] Suganda, R. D. Permatasari, Pratiwi, and I. Y. Panessai, "Sistem Informasi Pemantauan Retribusi Pada Menara Telekomunikasi", International Journal of Education, Science, Technology, and Engineering, vol. 2, no. 2, pp. 97 - 111, Dec. 2019. doi: 10.36079/lamintang.ijeste-0202.27

[32] Andreansyah, A. Rachman, and Rahmi, "Implementation of Incremental Models on Development of Web-Based Loan Cooperative Applications", International Journal of Education, Science, Technology, and Engineering, vol. 3, no. 1, pp. 26-34, Jun. 2020. doi: 10.36079/lamintang.ijeste-0301.105

[33] A. Ismail, N. Z. Mohamed Zain, and H. Mat Zin, "A Simple Survey on Attitude of Computer Science Diploma Students towards STEM", International Journal of Humanities, Management and Social Science, vol. 2, no. 2, pp. 76 - 88, Dec. 2019. doi: 10.36079/lamintang.ij-humass0202.35 